\title{
THE OVARY OF ROCK HYRAX OF THE GENUS PROCAVIA
}

\author{
F. I. B. KAYANJA AND J. B. SALE \\ Department of Veterinary Anatomy and Histology, and Department of Zoology, \\ University of Nairobi, P.O. Box 30197, Nairobi, Kenya
}

(Received 13th March 1972)

\begin{abstract}
Summary. Investigations of the reproductive tracts of thirty-five female Procavia collected in the Kenya Rift Valley over a 1-year period are reported. The seasonal nature of breeding in these populations is confirmed. Parturition is followed by a period of lactation anoestrus. The appearance and internal structure of the ovary is described, together with an account of oogenesis and follicular development. Follicle and oocyte are large at the end of the first phase of growth, possibly due to the accumulation of lipid droplets in the oocyte. There was a high incidence of transuterine migration of ova in these animals. Considerable atresia of tertiary follicles during early pregnancy was noted. The ovary of Procavia shows general similarities to that of Dendrohyrax.
\end{abstract}

\section{INTRODUCTION}

The hyraces (order: Hyracoidea) have long been a group of considerable zoological interest on account of their taxonomy and relationship to the elephants and ungulates, well established by the detailed fossil record of the order. Recent studies of their biology have revealed a number of unusual features in the living animal and its ecology.

Reproduction in the male has been investigated by Glover \& Sale (1968). In the female, the findings on gestation period ( $7 \frac{1}{2}$ months), litter weight, parturition behaviour and breeding season (Sale, 1965a, 1965b, 1969) are especially relevant to the present paper, but there is a lack of information on the female reproductive tract apart from reference to it in very general early descriptions of hyrax anatomy (George, 1874) and a recent paper by O'Donoghue (1963) on the female tree hyrax (Dendrohyrax).

The aim of the present study is to direct attention towards anatomical details of the reproductive tract that might throw light on function and also help to elucidate the phylogeny of this unusual group of mammals. The two genera of rock-dwelling hyraces (Procavia and Heterohyrax) display similar ecological characteristics, being diurnal herbivores that live in colonies on rocky outcrops and cliffs bearing suitable holes for shelter (Sale, 1966). Procavia is larger and anatomically distinct from Heterohyrax which shows close morphological affinities with the tree hyraces. 


\section{MATERIALS AND METHODS}

Rock hyrax belonging to the genus Procavia (and probably all of the species habessinica, Hemprich and Ehrenberg) were collected from Ngong Escarpment, Black Reef, Mt Suswa and Masai Gorge, all situated either along the Eastern Escarpment or on the floor of the Kenya Rift Valley. Altogether, thirty-five animals were collected between August 1970 and September 1971. Seven adult female hyrax were used for macroscopic investigation of the reproductive organs. The abdominal cavity was injected with $10 \%$ formalin soon after death and the animals were subsequently immersed in a tank containing $10 \%$ formalin after making an opening in the abdominal wall. Dissections were then carried out to reveal the reproductive organs.

Details of the twenty-eight animals used for histological investigations of the ovary are given in Table 1 . The length, breadth and depth of the ovaries were measured before they were fixed in Bouin's fluid or, occasionally, in $5 \%$ formalin. The paraffin-wax embedded sections were stained with haematoxylin and eosin, azan, the PAS reaction or by the Gomori technique for reticular fibres. Ten ovaries were fixed in formaldehyde-glutaraldehyde-trinitro fixative (Ito \& Karnovsky, 1968), post-fixed in osmium tetroxide and embedded in Epon-Araldite. Sections ( 1 to $2 \mu \mathrm{m}$ thick) were cut from the Epon-Araldite tissue blocks, stained with $3 \%$ toluidine blue in $1 \%$ borax and examined by light microscopy.

\section{RESULTS}

The breeding cycle

The populations of Procavia studied bred at slightly different times of the year as indicated in Table 1.

Black Reef Procavia. From the appearance of the ovaries, it is clear that this population mated during August and the beginning of September 1970. The young were born before June 1971 and the lactation period lasted until the beginning of the next mating season in September 1971, slightly later than the previous year.

Mt Suswa Procavia. The young were born during August 1970 and the lactation period lasted until the beginning of October when the mating season began.

Masai Gorge Procavia. The rock hyrax in this population mated during December 1970 and January 1971.

$\mathcal{N}$ gong Procavia. The mating season of this population was rather similar to that at Black Reef taking place during August and September 1970, during which time no histological material was taken. The young were born before June 1971, and the females were lactating until the end of August 1971.

Within each population, there was some synchronization of the mating season, parturition and lactation but this was within a matter of weeks rather than days.

The structure of the ovary

The ovaries of Procavia were found 2 to $3 \mathrm{~cm}$ caudal to and along a line 


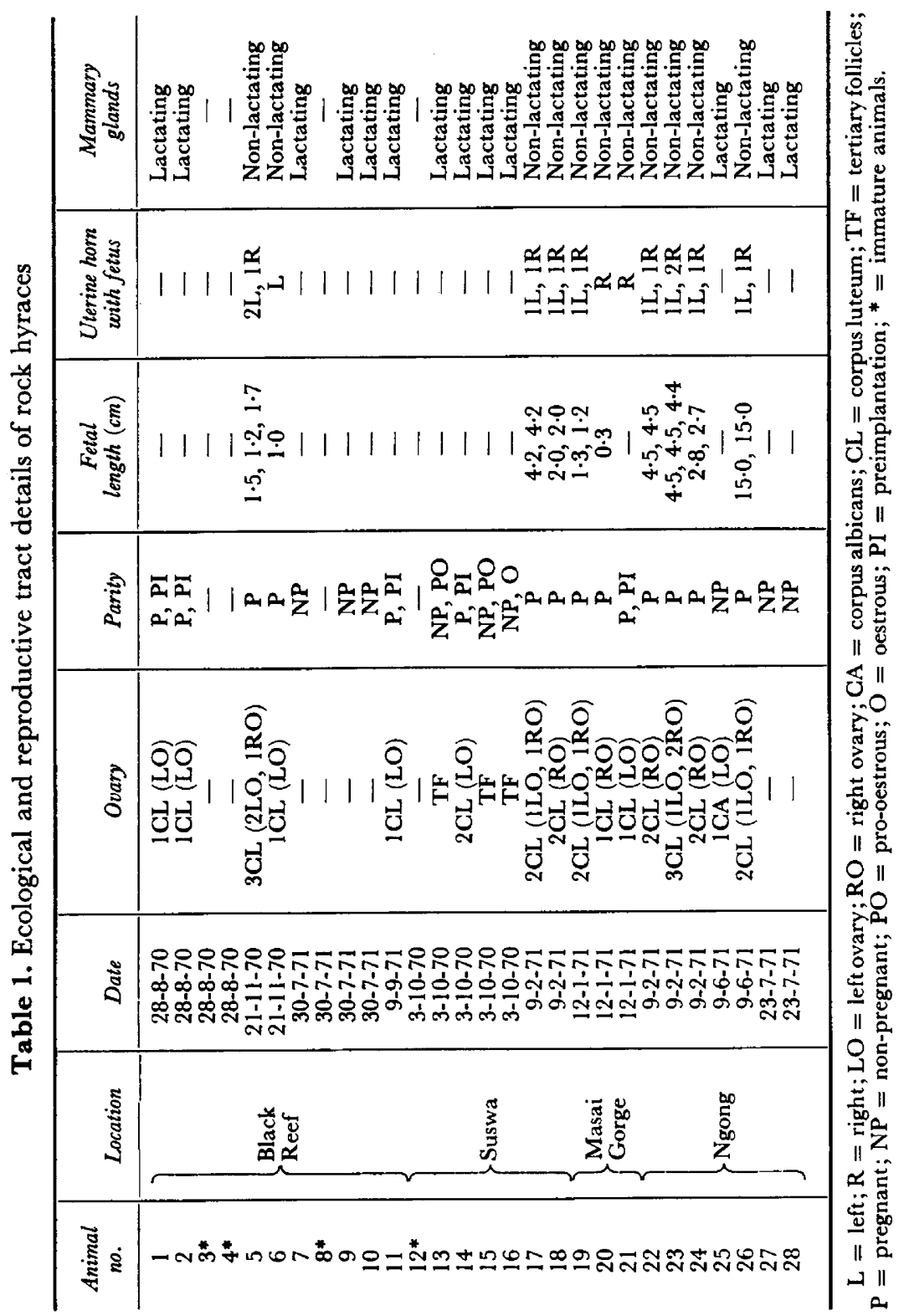


passing along the lateral border of the kidneys. They were related to the ventrolateral margin of the sub-lumbar muscles. The ovaries measured on the average $8 \mathrm{~mm}$ in length and $5 \mathrm{~mm}$ in breadth and $2 \mathrm{~mm}$ in depth and weighed $70 \mathrm{mg}$. Eckstein \& Zuckerman (1956) recorded measurements of $8 \times 4 \times 3 \mathrm{~mm}$ for Procavia.

The ovaries were almost completely covered by a thin and transparent mesosalpinx (Pl. 1, Fig. 1). This formed an extensive bursa ovarica with only a small opening found caudomedially and ventrally to the ovary (Pl. 1, Figs 2 and 3). Craniolaterally, the ovaries were related to the fimbriae and the infundibular portion of the oviduct. Coils of the isthmic portion of the oviduct lay caudal to and along the dorsolateral border of the ovary. The ligamentum ovarii proprium of Procavia was structurally part of the mesometrium. It originated from the ovary and faded out into the mesometrium before reaching the uterine horn of the same side.

As reported by Eckstein \& Zuckerman (1956), the ovaries of rock hyrax had a rough surface of 'foliate appearance'. This was most apparent during anoestrus and pregnancy. One to three corpora lutea were present during pregnancy. They were smooth spherical protrusions measuring about $2 \mathrm{~mm}$ in diameter and weighing about $12 \mathrm{mg}$ when fully formed (Pl. 1, Fig. 2). During pro-oestrus and especially at oestrus, the ovaries carried tertiary follicles forming smooth, fluid-filled swellings on the ovarian surface.

The ovary was covered by a germinal epithelium which varied between 5 and $10 \mu \mathrm{m}$ in height but was usually of a low cuboidal type. There were numerous invaginations of this epithelium into the subjacent cortex and especially near the mesovarium. Evaginations of the germinal epithelium containing a core of ovarian cortex were occasionally encountered. The tunica albuginea directly beneath the epithelium was well developed. The cortex lying below the tunica albuginea contained the ovarian follicles and corpora lutea and the medulla occupied the centre of the ovary (Pl. 1, Figs 3 and 4). The blood vessels entered and left the ovary through the mesovarium and the veins of this region had prominent valves.

The connective tissue of the ovary of Procavia, according to the arrangement of the reticular fibres, was composed of two separate systems. Within the medulla, the course of the fibres was largely determined by the arrangement of the connective tissue accompanying the tunica adventitia of the blood vessels. The reticular fibre construction of the ovary was such that the cortex formed an almost morphologically isolated segment of the ovary. Similar findings were

\section{EXPLANATION OF PLATE 1}

FIG. 1. A photograph showing the right ovary and oviduct of a rock hyrax. Note the extensive but delicate and transparent mesosalpinx $(\mathrm{m})$, ovary $(\mathrm{o})$ and the oviduct (ov). $\times 2 \cdot 5$.

FIG. 2. A photograph showing the right ovary carrying a fully developed corpus luteum. The mesosalpinx has been removed. Note the ovary (o), corpus luteum (cl) and the oviduct (ov). $\times 7$.

FIc. 3. A section through an ovary carrying a corpus luteum (cl). Note the bursa ovarica (bo), and the oviduct (ov). H. Azan. $\times 10$.

Fig. 4. A section through an ovary carrying a fully developed corpus luteum (cl). H. \& E. $\times 9$. 
PLATE 1
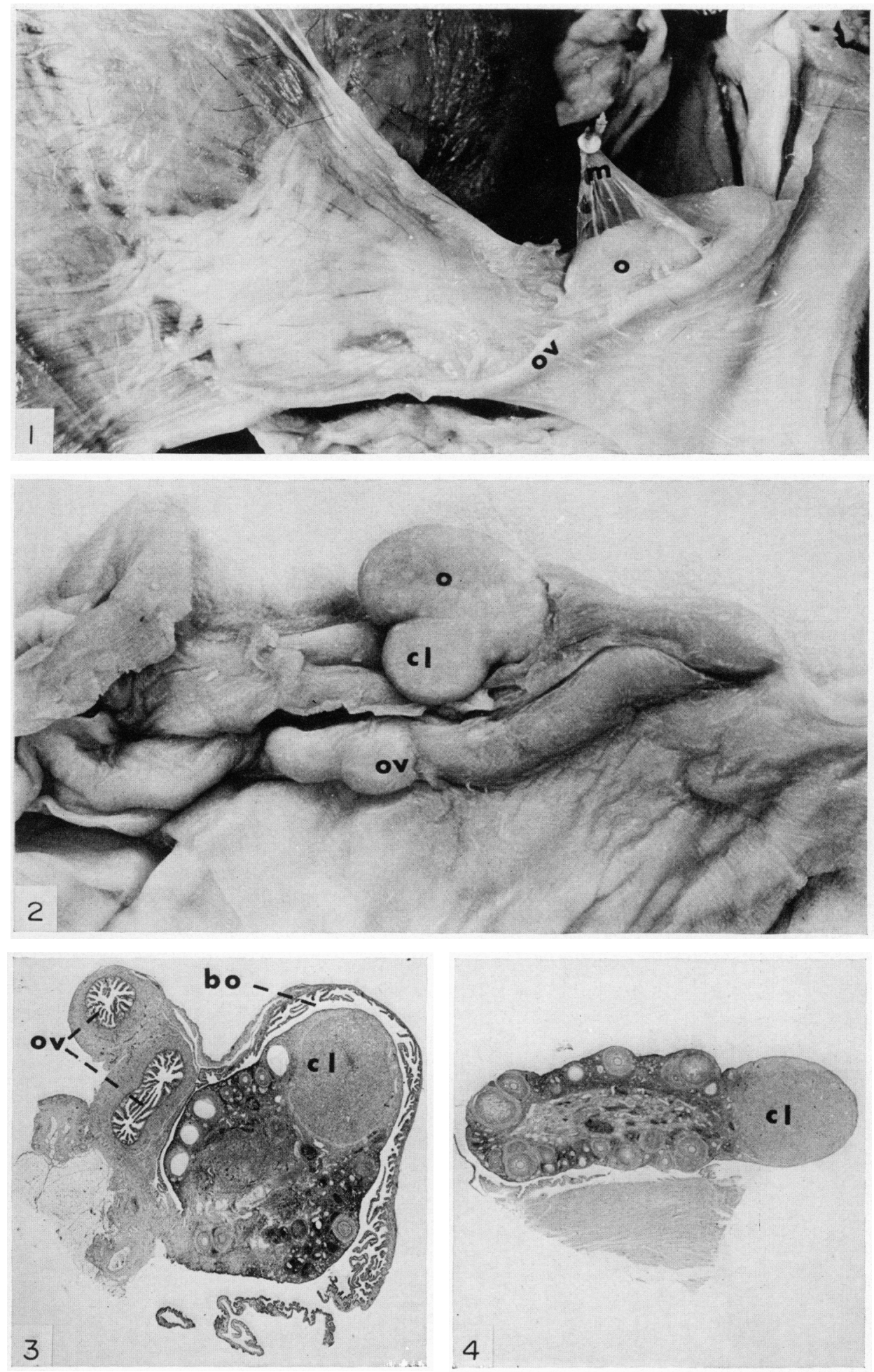
PLATE 2
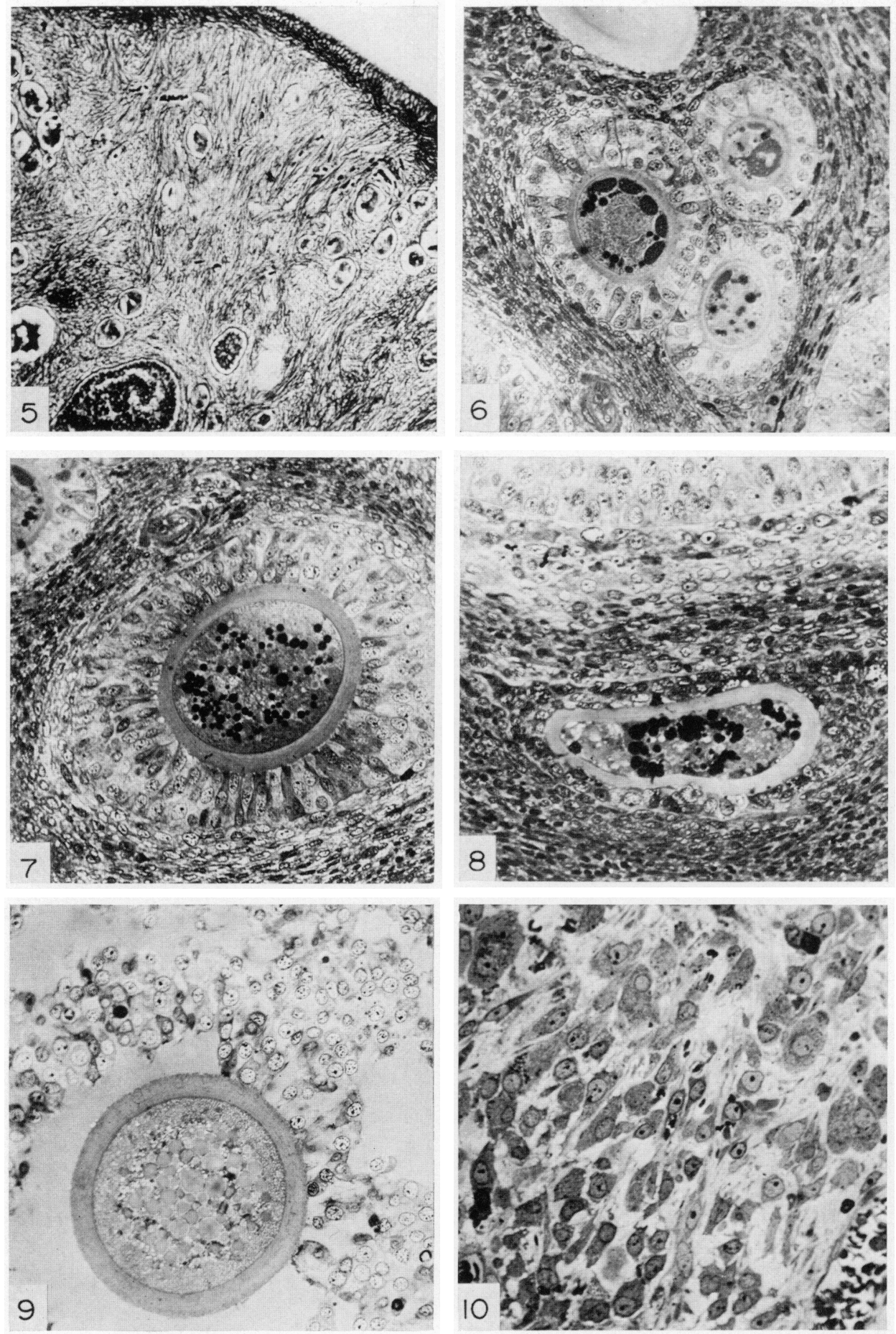

(Facing p. 227) 
recorded in the human ovary by Petry (1950) and in the ovary of the impala by Kayanja (1972). In the depth of the ovarian cortex, the reticular fibres were interwoven to form a three-dimensional system in which the follicles were lodged. This system was mainly arranged at right angles to the ovarian surface. The reticular fibres fanned out to run parallel to the ovarian surface as they approached it (Pl. 2, Fig. 5).

\section{Oogenesis and follicular development}

The smallest oocyte measured $17 \mu \mathrm{m}$ in diameter. A complete epithelial covering was acquired when the oocyte was about $20 \mu \mathrm{m}$ in diameter. The zona pellucida appeared when the oocyte measured $30 \mu \mathrm{m}$ and the follicle $55 \mu \mathrm{m}$ in diameter. This coincided with the stratification of the follicular epithelium. In follicles measuring about $85 \mu \mathrm{m}$ and containing oocytes of about $40 \mu \mathrm{m}$ in diameter, the zona pellucida was fully formed and measured around $10 \mu \mathrm{m}$ in thickness and was just over $14 \mu \mathrm{m}$ in thickness in the large tertiary follicles. During their development, the occytes acquired lipid droplets and mature ones contained a substantial amount of lipid.

The antrum developed when the follicle was just over $200 \mu \mathrm{m}$, and the oocyte was nearly $100 \mu \mathrm{m}$, in diameter. The growth rate of the follicle in relation to that of the oocyte was examined and found to be biphasic (Text-fig. 1). The regression lines were calculated from the following formulae:

$$
\mathrm{Y}=13 \cdot 11+0 \cdot 368 \mathrm{X}
$$

where $\mathrm{Y}$ is the diameter of the oocyte in $\mu \mathrm{m}$ and $\mathrm{X}$ is the diameter of the follicle between 25 and $225 \mu \mathrm{m}$; and

$$
\mathrm{Y}=90 \cdot 41+0 \cdot 034 \mathrm{X}
$$

where $\mathrm{Y}$ is the diameter of the oocyte in $\mu \mathrm{m}$ and $\mathrm{X}$ is the diameter of the follicle between 225 and $650 \mu \mathrm{m}$.

\section{Follicular atresia}

The atresia of tertiary follicles was most remarkable during early pregnancy. Usually, there was thinning of the membrana granulosa due to sloughing of its cells into the antrum. In some cases the granulosa was lost, leaving a cystic squamous-like epithelium.

The invasion of the granulosa by the theca interna was seen less frequently in Procavia than in the impala (Kayanja, 1969). When it occurred in hyrax, it

\section{EXPLANATION OF PLATE 2}

Fig. 5. A section through the cortex of a rock hyrax ovary showing the reticular fibre arrangements. Gomori. $\times 125$.

Fig. 6. A section through an ovary showing one primary and several early secondary follicles with lipid droplets in oocytes. Toluidine blue. $\times 250$.

FIG. 7. A section through an ovary showing a secondary follicle with lipid droplets in the oocyte. Toluidine blue. $\times 250$.

Fig. 8. A section through an ovary showing an atretic secondary follicle with lipid droplets in the oocyte. Toluidine blue. $\times 250$.

FIG. 9. A section through part of an atretic tertiary follicle. Toluidine blue. $\times 250$.

Fig. 10. A section through a corpus luteum before implantation. Toluidine blue. $\times 250$. 
was more localized than in the ruminants. Collapse of tertiary follicles and their eventual subdivision was occasionally encountered.

Atresia affecting the primary and secondary follicles was most apparent during anoestrus when these animals were lactating. Abnormal development was usually first detected by the appearance of increasing numbers of small lipid droplets within the cytoplasm. As the process progressed, there was an increase in the number and size of the lipid droplets (Pl. 2, Figs 6, 7 and 8). Accumulation of lipid droplets and vacuolation of the cytoplasm were also

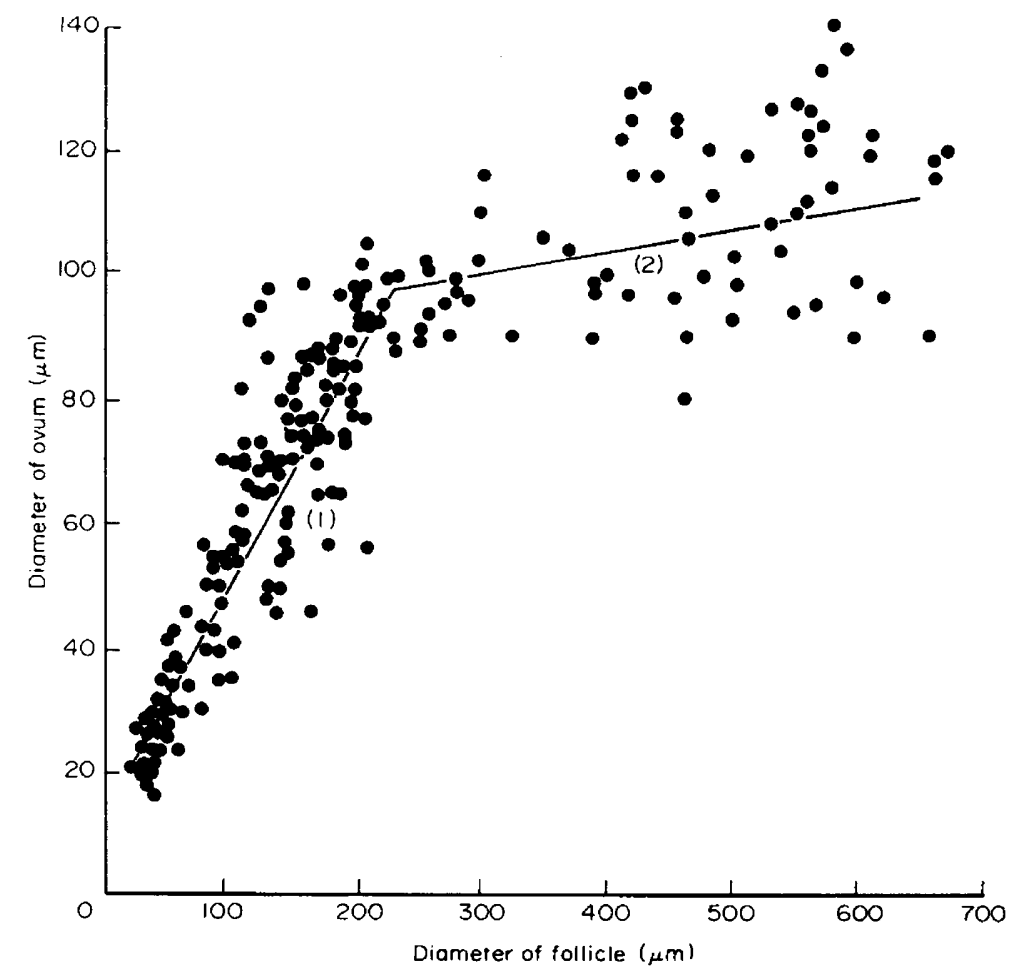

Text-fig. 1. The relationship between the growth of ovum and follicle in Procavia. See text for the formulae of regression lines (1) and (2).

seen in oocytes of atretic tertiary follicles (Pl. 2, Fig. 9). During lactation, the ovaries contained the largest amount of interstitial tissue from the results of the atresia, especially of the tertiary follicles.

\section{The corpus luteum}

In this investigation, thirteen corpora lutea were found in the left and thirteen in the right ovaries in fifteen pregnant rock hyrax with a total of twenty-six corpora lutea. There was a surprisingly high rate of migration of ova from the ovulation side to implant in the opposite uterine horn, as in Animals 18, 21, 22 and 24. It was only in Animal 21 that the single egg migrated from the side of ovulation to the opposite uterine horn (Table 1).

The corpora lutea were red, especially during early pregnancy and protruded 
along the ovarian surface (Pl. I, Figs 3 and 4). Before implantation, most of the cells of the developing gland measured about $12 \mu \mathrm{m}$ and contained nuclei of 7 to $8 \mu \mathrm{m}$ in diameter. These small cells had processes extending into the abundant intercellular substance (PI. 2, Fig. 10). Their spherical nuclei contained a distinct nucleolus and the cytoplasm had many small droplets staining intensely with toluidine blue.

At implantation, most of the luteal cells measured around $16 \mu \mathrm{m}$ and their nuclei were $8 \mu \mathrm{m}$ in diameter. The luteal cells were usually globular in shape. The postimplantation corpora lutea contained cells which varied in size from 16 to $25 \mu \mathrm{m}$ and with nuclei of $8 \mu \mathrm{m}$ in diameter. These usually globular luteal cells were more closely packed with only minimal intercellular spaces between them. Their spherical nuclei contained a distinct nucleolus and the gland was well vascularized.

\section{Abnormal development of follicles}

Binucleate primary and binovular tertiary follicles were the commonest of the rare abnormal follicles in the ovaries of Procavia.

\section{DISCUSSION}

According to the breeding season, the populations investigated could be divided into two groups. The first (Black Reef and Ngong) had peak parturition in June while the second group (Suswa and Masai Gorge) had peaks during the latter half of the year. This is almost entirely in agreement with the observations that Procavia living along the eastern wall of the Rift Valley show a parturition peak in June, while populations living on the Rift floor tend to have a dispersed pattern with a higher incidence during the latter half of the year (Sale, 1969). According to O'Donoghue (1963), there was no definite breeding season in Dendrohyrax although there were probably more births during the middle of the year. This conforms with what is known of other African forest species which display little or no seasonality in their breeding patterns.

Parturition is followed by a period of lactation during which the females are in anoestrus, as was also observed in Dendrohyrax by O'Donoghue (1963). The end of lactation coincides with the commencement of oestrous cycles.

Procavia shows an interesting incidence of the migration of ova from the side of the ovulation to the opposite uterine horn, which was also reported in Dendrohyrax by O'Donoghue (1963). Kelly \& Eckstein (1966) reported that, in the mare, the egg frequently moved to the opposite uterine horn. When two ova are released from a single ovary in the sheep, one generally migrates and implants in the contralateral uterine horn (Boyd, Hamilton \& Hammond, 1944). This phenomenon, known as transuterine migration, occurs in a large number of mammals according to Boyd \& Hamilton (1952). The elaborate bursa ovarica of the hyrax indicates that the migration is more likely to be transuterine rather than across the peritoneum.

The ovary of Procavia is smaller but otherwise similar in structure to that of Dendrohyrax as described by O'Donoghue (1963). As in Dendrohyrax, the corpora lutea are formed by ovulation in Procavia. The diversity of cell types in the 
early corpora lutea of Procavia may be an indication that they are not entirely derived from the theca interna and ultrastructural investigations taking place at this time have strengthened this suggestion. O'Donoghue (1963) concluded that all luteal tissue was derived exclusively from the thecae internae of ruptured follicles in Dendrohyrax.

Brambell (1956) indicated that, independently of the body size of the species, the size of the follicle and oocyte at the end of the first phase of growth varied according to the amount, always small, of reserve material within the cytoplasm. The follicle and oocyte of Procavia are somewhat large at the end of the first phase of growth. It is possible that the lipid content of the oocyte contributes to its large size. This size is of especial interest in association with the long gestation period for a relatively small animal (Sale, 1965b).

During its development, the oocyte gradually accumulates lipid droplets, the rate of accumulation appearing to be crucial for the survival of the oocyte and follicle. It is not yet clear why precocious development of lipid droplets is associated with atresia in Procavia. An ultrastructural investigation now in progress may throw some light on this observation.

\section{AGKNOWLEDGMENTS}

Our most grateful thanks are due to Dr W. B. Neaves for help in collecting the material and also to Miss J. Jhite for technical assistance.

\section{REFERENGES}

Boyd, J. D. \& Hamilton, W. J. (1952) Cleavage, early development and implantation of the egg. In: Marshall's Physiology of Reproduction, Vol. 2, Chapter 14. Ed. A. S. Parkes. Longmans, London.

Boyd, J. D., Hamilton, W. J. \& Hammond, J., JR (1944) Transuterine (internal) migration of the ovum in sheep and other mammals. F. Anat. 78, 5.

Brambeli, F. W. R. (1956) Ovarian changes. In: Marshall's Physiology of Reproduction, Vol. 1, Part 1, Chapter 5. Ed. A. S. Parkes. Longmans, London.

Eckstein, P. \& Zuckerman, S. (1956) Morphology of the reproductive tract. In: Marshall's Physiology of Reproduction, Vol. 1, Part 1, Ghapter 2. Ed. A. S. Parkes. Longmans, London.

George, M. (1874) Monographie anatomique des mammifères du genre Daman. Annls Sci. nat.Zool., (6) 1,1 .

Glover, T. D. \& SALE, J. B. (1968) The reproductive system of male rock hyrax (Procavia and Heterohyrax). F. Zool., Lond. 156, 249.

Ito, S. \& Karnovsky, M. J. (1968) Formaldehyde-glutaraldehyde fixatives containing trinitro compounds. F. Cell Biol. 39, 168a.

Kayanja, F. (1969) The ovary of the impala, Aepyceros melampus (Lichtenstein, 1812). F. Reprod. Fert. Suppl. 6, 311.

Kayanja, F. (1972) Reproduction in antelopes. Reproduction in the female impala (Aepyceros melampus, Lichenstein, 1812). East African Monographs in Biology Series. Ed. T. R. Odhiambo. East African Literature Bureau, Nairobi.

Kelly, W. A. \& Eckstein, P. (1966) Implantation, fetus and fetal membrane. In: Reproduction in Domestic Animals, 2nd edn. Eds. H. H. Cole and P. T. Cupps. Academic Press, New York and London.

O'Donoghue, P. N. (1963) Reproduction in the female hyrax (Dendrohyrax arborea ruwenzorii). Proc. zool. Soc. Lond. 141, 207.

Petry, G. (1950) Die Konstruktion des Eierstockbindegewebes und dessen Bedeutung für dem Ovariellen Zyklus. Z. Zellforsch. mikrosk. Anat. 35, 1.

SALE, J. B. (1965a) Gestation period and neonatal weight of the hyrax. Nature, Lond. 205, 1240.

SAle, J. B. (1965b) Parturition and related phenomena in the hyrax (Procaviidae). Acta trop. 22, 37.

SALE, J. B. (1966) The habitat of the rock hyrax. Fl E. Africa nat. Hist. Soc. 25, 205.

Sale, J. B. (1969) Breeding season and litter size in Hyracoidea. F. Reprod. Fert. Suppl. 6, 249. 